\title{
EDITORIAL
}

\section{Simple sequential treatment for primary spontaneous pneumothorax: one step closer}

\author{
M.T. Henry
}

$\mathbf{P}$ rimary spontaneous pneumothorax (PSP) remains a significant clinical problem in emergency departments and respiratory medicine units. The management of minimally symptomatic patients presenting with their first small PSP on a chest radiograph is straightforward; a period of simple observation with follow-up chest radiography will usually suffice. Attempts to prevent recurrence at this stage are generally not recommended, as $50-70 \%$ of these patients will not have a recurrence [1-3]. However, despite literature replete with discussions on the assessment and management of PSP, no standard approach to symptomatic or "large" PSPs has been universally adopted. Two significant guidelines for management of pneumothoraces have addressed this problem, one of which was evidence-based and the other consensusbased $[4,5]$.

Objectives for managing these patients should be straightforward. Ideally, a diagnosis and treatment algorithm should be adopted that would predict those who need intervention. It should facilitate the treatment and discharge of a significant proportion of these patients in the emergency department without the need for hospital admission. It should also allow for continuing management of patients who require in-patient pleural drainage without further invasive procedures, until it becomes apparent that they have a persistent air leak necessitating surgical intervention. Finally, these young and otherwise fit patients should be managed in a setting that allows them to remain mobile during their pleural drainage.

Predicting which patients require treatment for their PSPs seems relatively straightforward. Breathless patients or those with persistent significant chest pain should not be left without intervention, regardless of the size of the pneumothorax on the chest radiograph [4,6]. What is less apparent is when to intervene in clinically stable patients with large pneumothoraces. The definition of what constitutes a large pneumothorax varies, with the American College of Chest Physicians (ACCP) defining it as $\geqslant 3 \mathrm{~cm}$ apex to cupola distance [5], but the British Thoracic Society (BTS) stating that it is $\geqslant 2 \mathrm{~cm}$ between the lung margin and the chest wall [4]. The latter definition derives from the Light index (\% pneumothorax $\left.=100-\left(\mathrm{DL}^{3} / \mathrm{DH}^{3} \times 100\right)\right)$ which has been shown to correlate accurately with the volume of air inside the pleural cavity [7] and depends on the ratio of cubed diameters (D) of the deflated lung (L) and hemithorax (H). The BTS definition

CORRESPONDENCE: M.T. Henry, Dept of Respiratory Medicine, Leeds General Infirmary, Leeds, LS1 3EX, UK. Fax: 44 1133926316. E-mail: michael.henry@leedth.nhs.uk suggests that if the lung deflates uniformly from the chest wall by $\geqslant 2 \mathrm{~cm}[4,8]$, then it is very likely that the volume of air will be $>50 \%$ of the volume of the hemithorax. Both definitions are unwieldy and as the lung does not often deflate in a uniform manner around the whole circumference, all such equations are unreliable. In the current issue of the European Respiratory Journal, MARQUETTE et al. [9] provide a simplified approach to the management of PSP. It is interesting that the authors note that in their population of 41 consecutive PSP patients, $98 \%$ would be defined as large pneumothoraces using ACCP criteria but only $68 \%$ would be defined as such according to BTS criteria, suggesting that fewer patients would be treated invasively using BTS criteria for PSP assessment. This suggests that the BTS criteria may underestimate the volume of a pneumothorax. Discussion between C.H. Marquette and M. Noppen (personal communications; Hôpital Albert Calmette, Lille, France and Academic Hospital AZ-VUB, Brussels, Belgium, respectively), who are experts in this field, has highlighted that in an era of increasing access to digital imagery such equations are likely to become obsolete. A personal communication with $\mathrm{M}$. Noppen has provided what seems to be a very sensible and useful definition of what constitutes a large pneumothorax ("complete dehiscence of the lung from the chest wall") and a small pneumothorax ("partial dehiscence"). This practical description of pneumothorax size correlates well with the experience of most respiratory physicians trying to draw a relationship between physical and radiological findings. It would make the decision to treat a pneumothorax based on size rather than symptoms a less complicated one, particularly for junior colleagues in training, who may struggle with the various equations outlined above. While there is consensus that treatment is required for all symptomatic primary pneumothoraces, treatment of large pneumothoraces in clinically stable patients may be facilitated by universally adopting a chest radiograph grading system such as that suggested here.

Once the decision to treat a patient with a PSP has been made, the therapeutic options for evacuating air from the pleural space include: 1) simple aspiration with a cannula and threeway tap, and removal of the cannula after full, or almost full, evacuation of air; 2) insertion of a small bore catheter into the pleural space using the "Seldinger" technique; or 3) insertion of a large chest tube into the pleural space $[6,8,10]$. The BTS guidelines recommend simple aspiration with subsequent reaspiration in selected cases, progressing to the insertion of an intercostal drain if simple aspiration fails [4]. The use of smallcalibre chest drains is favoured over the traditional larger 
tubes. The ACCP Delphi consensus document recommends a $16 \mathrm{~F}$ to $22 \mathrm{~F}$ chest tube or small-bore catheter (good consensus for both) depending on the degree of clinical instability, with larger tubes recommended if the patient is felt to have a bronchopleural fistula [5]. Both guidelines recommend a water seal device initially with attachment to suction if the lung fails to re-expand, although the ACCP suggests that a small-bore catheter attached to a Heimlich valve may be an option if clinical stability can be obtained.

As it is now 3 and 5 yrs respectively since the publication of the BTS and ACCP documents [4,5], it is perhaps appropriate to review the evidence supporting these particular guidelines and to ask ourselves whether we may now suggest an evidence-based simple treatment algorithm that would facilitate the treatment objectives outlined above. Simple aspiration using a 16-18-gauge catheter inserted under local anaesthetic, aspirating air through a three-way tap with the exit tube underwater, has been shown, in several randomised and noncontrolled trials [11-14] of primary and mixed primary and secondary pneumothoraces, to be an effective alternative to intercostal tube drainage. Success rates of $\sim 60 \%$, comparable lengths of hospital stay and recurrence rates at $1 \mathrm{yr}$ after the first PSP of $17-26 \%$ have been demonstrated [11, 13-15]. In practice, however, the aspiration cannula frequently kinks in inexperienced hands and requires a second or third attempt, and the procedure is cumbersome and does not effectively exclude a persistent air leak. It is also difficult to successfully keep the sealed catheter in place while a follow-up chest radiograph is obtained prior to removal and discharge.

Catheter aspiration systems using Seldinger insertion techniques are now widely used in the management of spontaneous pneumothoraces. They are attached variously to three-way taps and syringes for simple aspiration, flutter valves, Heimlich valves or underwater seal systems [16-18]. These techniques have minimal morbidity, allow early discharge of a significant minority of patients and may enable the continuation of therapy through a sequential approach, albeit at a slightly higher financial cost than "simple" aspiration. Negative pressure suction may be added to the system in those who do not achieve full re-expansion of the lungs after $24 \mathrm{~h}$, as demonstrated by VALLEE et al. [19] as early as 1988. In their pilot study, MARQUETTE et al. [9] demonstrate a single aspiration system that facilitates a simplified sequential steps approach to the treatment of these patients using an $8.5 \mathrm{~F}$ catheter attached to a Heimlich one-way valve rather than an underwater seal system. The catheters were inserted using the Seldinger technique in 41 consecutive PSP patients. Patients were admitted and negative pressure suction was added for failure of lung re-expansion at $24-48 \mathrm{~h}$, as was subsequent referral to the thoracic surgeons after 4 days for persistent air leak as per the BTS guidelines [4]. The authors demonstrated that with this approach only one invasive procedure was required, large tube thoracostomy was avoided and over a third of patients would have been suitable for discharge at $6 \mathrm{~h}$, with $61 \%$ of patients having full lung re-expansion after $24 \mathrm{~h}$ and thus being suitable for discharge without further intervention.

This study provides further evidence to support the development of simple sequential treatment strategies for patients with
PSP, which is usually just a nuisance rather than a lifethreatening event. Replacing the Heimlich valve with an underwater seal system in the emergency department would perhaps more accurately identify the cessation of the air leak. Four to six hours of underwater seal drainage through a catheter aspiration system, followed by a chest radiograph, would allow those who have had a successful outcome to have the catheter removed and to be discharged safely. Thereafter, those who have an obvious persistent air leak on underwater seal or failure of full re-expansion could have the system replaced by the Heimlich valve. As MARQUETTE et al. [9] have shown, these patients remain mobile and comfortable with this system. They could be allowed home from the emergency department to return after a further $24-48 \mathrm{~h}$ for further chest radiography and clinical assessment, followed either by removal of the catheter or admission for negative pressure suction or surgical intervention if air leak persists beyond 4 days.

In conclusion, the pilot study presented by MARQUETTE et al. [9] in this issue of the European Respiratory Journal brings us one step closer to developing a universally accepted, predominantly outpatient-based protocol for the management of primary spontaneous pneumothorax. While treatment strategies will always have to be tailored to the individual patient, emerging evidence, including that provided here, should encourage us to develop further trials to facilitate the creation of a simple sequential algorithmic approach to the general management patients with primary spontaneous pneumothorax $[9,14]$.

\section{REFERENCES}

1 Sadikot RT, Greene T, Meadows K, Arnold AG. Recurrence of primary pneumothorax. Thorax 1997; 52: 805-809.

2 Lippert HL, Lund O, Blegrad S, Larsen HV. Independent risk factors for cumulative recurrence rate after first spontaneous pneumothorax. Eur Respir J 1991; 4: 324-331.

3 Scramel JFMN, Postmus PE, Vanderschueren RG. Current aspects of spontaneous pneumothorax. Eur Respir J 1997; 10: 1372-1379.

4 Henry MT, Arnold T, Harvey J, for the BTS Standards of Care Committee. BTS Guidelines for the management of spontaneous pneumothorax. Thorax 2003; 58: Suppl. 2, 39ii-58ii.

5 Baumann MH, Strange C, Heffner JE, et al. Management of spontaneous pneumothorax. An American College of Chest Physicians Delphi Consensus Statement. Chest 2001; 119: 590-602.

6 Sahn SA, Heffner JE. Spontaneous neumothorax. N Engl J Med 2000; 342: 868-873.

7 Noppen M, Alexander M, Driesen P, et al. Quantification of the size of primary spontaneous pneumothorax: accuracy of the Light index. Respiration 2001; 68: 396-399.

8 Light RW. Management of spontaneous pneumothorax. Am Rev Respir Dis 1993; 148: 245-248.

9 Marquette C-H, Marx A, Leroy S, et al. Simplified stepwise management of primary spontaneous pneumothorax: a pilot study. Eur Respir J 2006; 27: 470-476. 
10 Noppen M, Baumann MH. Pathogenesis and treatment of primary spontaneous pneumothorax: an overview. Respiration 2002; 70: 431-438.

11 Harvey J, Prescott RJ, on behalf of the BTS research committee. Simple aspiration versus intercostal tube drainage for spontaneous pneumothorax in patients with normal lungs. BMJ 1994; 309: 1338-1339.

12 Maury E, Droyon F, Guidet B, Moty A, Offenstadt G. Drainage of spontaneous pneumothorax using an intravenous catheter. Immediate and long-term results. Respir Med 1998; 92: 961-962.

13 Andrivert P, Djedaini K, Teboul J-L, Brochard L, Dreyfuss D. Spontaneous pneumothorax: comparison of thoracic drainage versus immediate or delayed needle aspiration. Chest 1995; 108: 335-340.

14 Noppen M, Alexander P, Driesen P, Slabbynck H, Verstraeten A. Manual aspiration versus chest tube drainage in first episodes of primary spontaneous pneumothorax. Am J Respir Crit Care Med 2002; 165: 1240-1244.

15 Light RW. Manual aspiration: the preferred method for managing primary spontaneous pneumothorax. Am J Respir Crit Care Med 2002; 165: 1202-1203.

16 Delius RE, Obeid FN, Horst HM, Sorensen VJ, Fath JJ, Bivins BA. Catheter aspiration for simple pneumothorax. Arch Surg 1989; 124: 833-836.

17 Minami H, Saka H, Senda $K$, et al. Small calibre catheter drainage for spontaneous pneumothorax. Am J Med Sci 1992; 304: 345-347.

18 Bevelaqua FA, Aranda C. Management of spontaneous pneumothorax with small lumen catheter manual aspiration. Chest 1982; 81: 693-695.

19 Vallee P, Sullivan M, Richardson H, Bivins B, Tomlanovich M. Sequential treatment of a simple pneumothorax. Ann Emerg Med 1988; 17: 936-942. 